\title{
Experimental Study on Characterization of Ground Heat Exchange Pipe Thermal Deformation
}

\author{
Renzhu Wang \\ ${ }^{1}$ Architectural Design Institute, Jilin \\ Architecture and Civil Engineering \\ Institute, \\ Changchun 130000, China
}

\author{
Youtang Wang ${ }^{2, *}$ \\ ${ }^{2}$ School of Architectural Engineering, \\ Shandong University of Technology, \\ Zibo 255049, China
}

\author{
Qing $\mathrm{Gao}^{3}$ \\ ${ }^{3}$ Department of Thermal Energy \\ Engineering, Jilin University, \\ Changchun 130025, China
}

\begin{abstract}
The study on thermal deformation of heat exchange pipe fixed in borehole was implemented. The thermal deformation of pipe buried in backfill was measured, and three typical shapes of pipe in non-backfilled borehole were selected to research thermal deformation behavior when they were suffering in heating process. It indicated that the pipes in different initial shapes showed different deformation behavior. Further analysis of the results indicated that frequent thermal deformation of pipe could result in impacts on the structure of ground heat exchange system, which will be the important factor for the performance degradation and reliability reduction.
\end{abstract}

Keywords-ground heat exchanger; pipe; thermal deformation; experiment.

\section{INTRODUCTION}

The huge rock-soil body in shallow underground offers an effective way of renewable usage for energy by various means. For this reason, the technologies and application of ground source heat pump (GSHP) and underground thermal energy storage (UTES) have been promoted and developed rapidly, especially in some areas in China[1]. For underground structure, the capacity of heat transfer will decrease after long-time operation that probably comes from thermal deformation and thermal micro displacement of buried pipes in borehole and the crevice or crack of backfill structure. Thus, the gradual performance degradation of ground heat exchange system is getting more and more prominent $[2,3]$. Therefore, the basic researches of the thermal strain and failure of heat exchange system from structure defect are proposed and implemented.

Temperature difference will increase with the development of technologies of ground energy usage, meanwhile, thermal deformation of underground heat exchange structure will appear more and more obviously. Therefore, it is necessary to develop the study of thermal deformation of heat exchange structure. Through the study, thermal deformation behavior of borehole pipe was investigated, so coping strategies could be put forward as to ensure the reliability of UTES and GSHP after long-time operation. In this paper, the source of structure deformation was demonstrated by measuring the displacement of pipe in simulated backfilled borehole. What's more, the basic characteristics of thermal deformation behavior of pipe were studied by visual experiment with pipes in non-backfilled borehole under large temperature difference.

\section{EXPERIMENTAL FACILITIES AND METHOD}

This experimental study took loose backfill and non-backfill as an example, the former basically is practical in more engineering, and the latter is beneficial to the visualization of deformation measurement as reference. The experimental system was designed and set up, as shown in Fig.1, to demonstrate the thermal deformation existing in heat exchange pipe and to study the tendency and pattern of thermal deformation of borehole pipe in heating process. The system consists of borehole pipe structure, temperature controlled water tank, circulating pump, adjusting valves, electronic turbine flow meter, thermocouples, resistance strain gages, camera, etc. The borehole pipe structure was built with heat exchange pipe inside a transparent plexiglass tube, which simulated the rigid borehole, while the top end and bottom end of the pipe were fixed in a bracket by fastening unit. The experimental heat exchange pipe is made from HDPE, its effective length is $2 \mathrm{~m}$, the outer diameter and thickness is $32 \mathrm{~mm}$ and $3.5 \mathrm{~mm}$ respectively. The transparent plexiglass tube is $2 \mathrm{~m}$ by length and $150 \mathrm{~mm}$ by inner diameter. Two thermocouples were located at the inlet and outlet of pipe to measure fluid temperature.

Based on this experimental system, firstly, the thermal deformation of pipe in backfilled borehole was measured indirectly by strain in pipe wall, secondly, thermal deformation behavior of pipe in non-backfilled borehole was maximized. In future experiment, different backfill conditions will be carried out on the basis of this system to study pipe deformation and backfill cracks, etc.

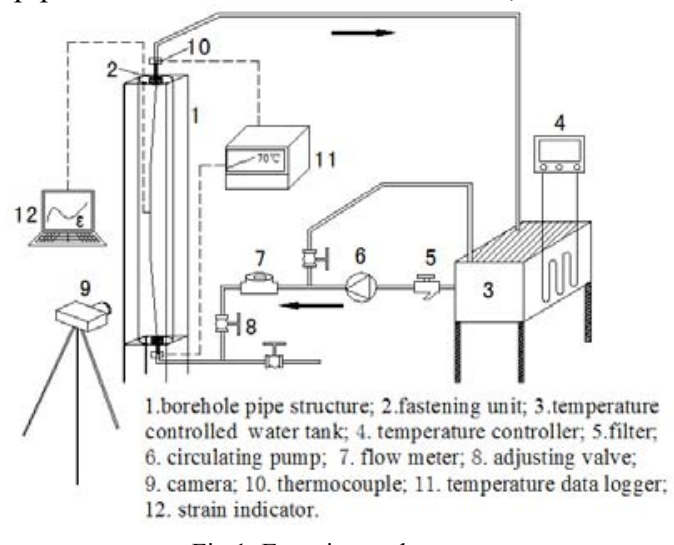

Fig.1. Experimental system 

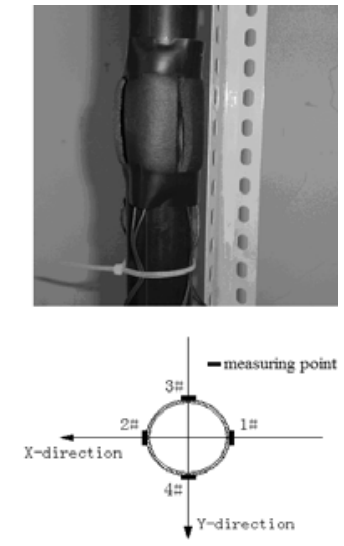

Fig.2. Strain measuring point

\section{A. Practical Backfill Experiment}

The backfill material in borehole is dry fine sand, and the grain diameter is $0.075 \sim 1 \mathrm{~mm}$. The ambient air temperature was maintained at $10{ }^{\circ} \mathrm{C}$, and the fluid temperature was increased in stages from $10^{\circ} \mathrm{C}$ to $50^{\circ} \mathrm{C}$. The strains in pipe wall were monitored by 24 resistance strain gages, installed at 6 pre-selected test locations along the pipe length. There were 4 symmetrical test points in each test location, which created a system of rectangular coordinates in horizontal plane, as shown in Fig.2, the displacement of $\mathrm{X}$-direction was determined by test point $1 \#$ and 2\#, while the displacement of Y-direction was determined by $3 \#$ and $4 \#$. These strain gages were monitored every $10^{\circ} \mathrm{C}$ increment by 3 strain indicators, then the continuous strains along the pipe length were determined by interpolation method. Finally, the continuous deformation and displacement of pipe was derived by differential geometry law. The more detailed derivation process was given by literatures[4,5,6].

\section{B. Visualization Experiment}

Due to the fact that thermal deformation is often affected by the ever-changing initial shape of borehole pipe, three typical initial shapes of pipe were selected as research objects, which were named as: (a) arc-shaped; (b) small S-shaped; (c) large S-shaped, as shown in Fig. 4 6. The initial bend of (a) and (b) appeared in photographic front view plane mainly, in which almost all the thermal deformation occurred and was analysed. The initial bend of (c), which was a space structure, appeared in both photographic front view and side view, consequently, the thermal deformation was analysed in both planes.

The ambient air temperature was maintained at $25^{\circ} \mathrm{C}$, and the heating process was implemented. During the process, the fluid temperature was increased in stages from $25^{\circ} \mathrm{C}$ to $70^{\circ} \mathrm{C}$. The camera, fixed in front of borehole pipe structure, recorded the pipe deformation with temperature changes. In addition, the thermal behavior of pipe in photographs was measured by computer-aided software to investigate the degree of pipe deformation.

\section{RESULTS AND DISCUSSIONS}

\section{A. Basic Thermal Deformation of a Practical Buried Pipe}

According to the method of pipe's thermal deformation measuring on the basis of thermal strain [6], the displacement of pipe's deformation along pipe length was shown in Fig. 3. Thermal deformation appeared in both $\mathrm{X}$-direction and Y-direction and the displacement increased with the increment of temperature $\mathrm{T}$. The results showed that even the displacement was not so remarkable, thermal deformation was demonstrated in pipe buried in backfill. However, the capacity of heat exchange system might be severely affected by the thermal deformation, especially for long-time operation with large temperature difference.

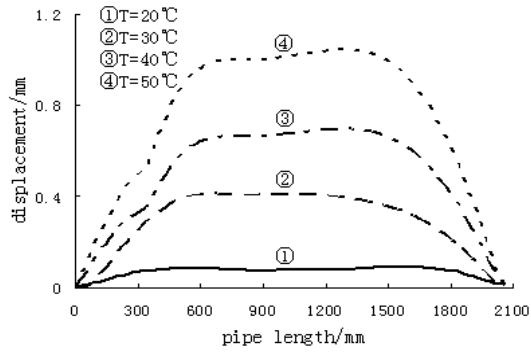

(a) X-direction

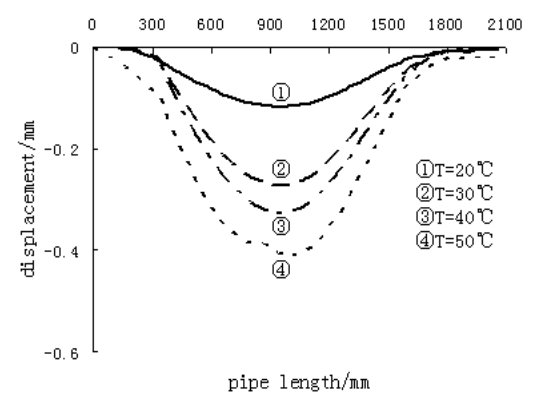

(b) Y-direction

Fig.3. The displacement of pipe's deformation

\section{B. Deformation Visualization and its Behavior Characterization}

\section{1) Experiment of arc-shaped}

In this experiment, the borehole pipe in arc-shaped was bended in plane as a single arc, and the middle section contacted the wall of tube closely. Initially, the length of contact surface ab was $600 \mathrm{~mm}$. The elongation of arc-shaped pipe could not release because of the constraint of tube, which resulted in the length of contact surface increasing with the increment of pipe inlet temperature $\mathrm{T}$, as shown in Fig. 4. The length of contact surface ab almost increased linearly in the experiment, which can be found in Fig. 4(b). 


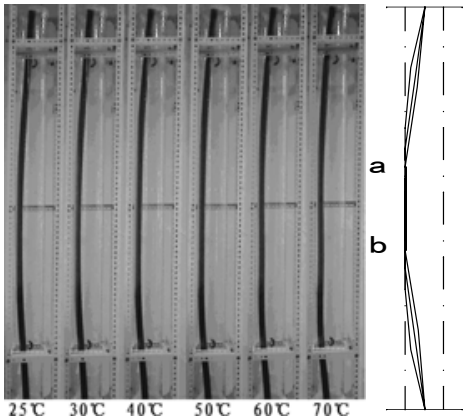

(a) Analytical chart

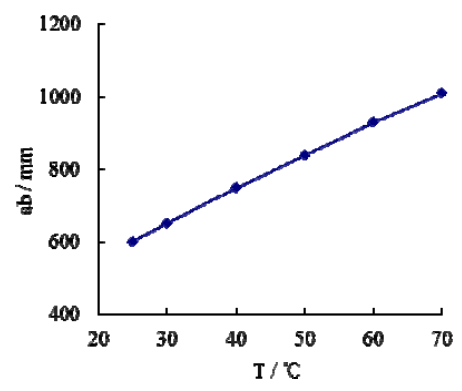

(b) The length of contact surface

Fig.4. Thermal deformation of borehole pipe in arc-shaped

It is showed that the pipe's thermal deformation was obvious in heating process. The increase of contact surface length means interactional squeeze between pipe and soil-rock was developing. Actually, affected by the varied squeeze load and frequent micro displacement, the cross section of pipe will show ovalization deformation in radial direction, which could result in overflow of circulating fluid and drop in fluid circulation [7].

\section{2) Experiment of small S-shaped}

The borehole pipe in small S-shaped looked like an overturned letter $\mathrm{S}$ in plane, its upper section located in the center of the tube, while the pipe contacted with the tube at point A which located at lower section, as shown in Fig. 5(a). It can be observed clearly that although the upper and middle section of pipe generated larger deformation, there was no distinct transformation occurred in the lower section including the contact point $\mathrm{A}$. In fact with the increment of temperature $\mathrm{T}$, both the elongation of pipe and constraint of tube resulted in a more developed $\mathrm{S}$ shape. Especially, when the temperature $\mathrm{T}$ increased to $60^{\circ} \mathrm{C}$, a new contact point $\mathrm{B}$ turned up, and then the length of contact surface in $\mathrm{B}$ increased until the temperature $\mathrm{T}$ increased to $70^{\circ} \mathrm{C}$. In order to investigate the degree of pipe deformation, the obliquity was defined as the angle $\alpha$ between the pipe section $\mathrm{AB}$ and the axis of tube in photo plane, shown in Fig. 5(a). The obliquity a increased almost linearly in the experimental temperature range, which can be found in Fig. $5(b)$.

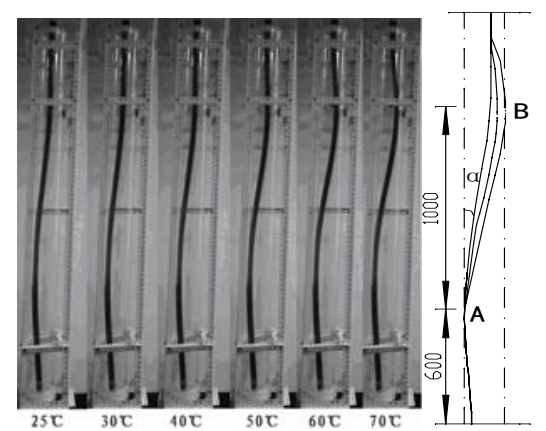

(a) Analytical chart

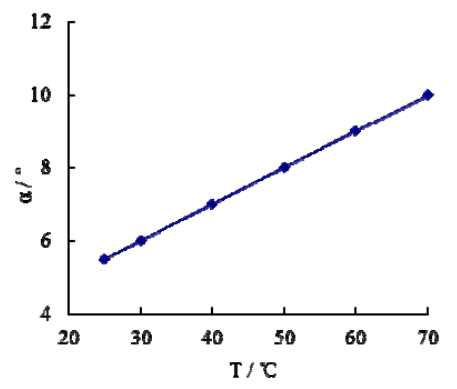

(b) The obliquity $\alpha$

Fig.5. Thermal deformation of borehole pipe in small S-shaped

Apparently, except for the difference in deformation behaviour, the above-mentioned borehole pipes with two shapes manifest similar in-plane thermal expansion and elongation in heating process.

\section{3) Experiment of large S-shaped}

The borehole pipe in large S-shaped was not bending in plane but space structure with slight spiral. In front view, the pipe appeared as an overturned letter $\mathrm{S}$ and had two initial contact points in the upper and lower section, as shown in Fig. 6(a). In side view, which is perpendicular to the front view, the pipe appeared as an inconspicuous letter $\mathrm{S}$ and had no initial contact point with tube, as shown in Fig. 6(b).

From the photograph of heating process, it is obviously that there was no remarkable transformation in front view, on the contrary, larger deformation manifested as increasing obliquity $\alpha$ of the middle pipe section appeared in side view. The obliquity $\alpha$ increased almost linearly, which can be found in Fig. 6(c). Especially, two new contact points $A^{\prime}$ and $\mathrm{B}^{\prime}$ turned up in the end of heating process. The upper point $\mathrm{B}^{\prime}$ was $435 \mathrm{~mm}$ away from the top end and the lower point $A^{\prime}$ was $720 \mathrm{~mm}$ away from the bottom end. It can be known that both the pipe elongation and constraint of tube resulted in a further developed spiral space structure. 


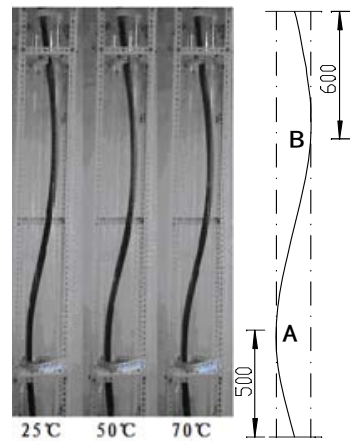

(a) Front view

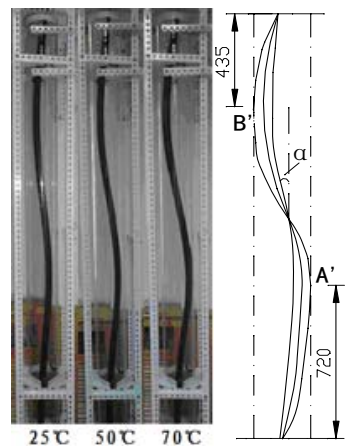

(b) Side view

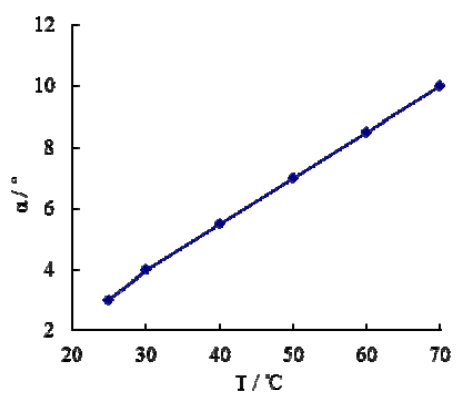

(c) The obliquity $\alpha$

Fig.6. Thermal deformation of borehole pipe in large S-shaped

It is known through further analysis that if the fluid temperature keeps on increasing, there will be more contact surface involved in the spiral space structure, that will cause more pipe section to be subject to interactional squeeze and wear-down. In comparison of small S-shaped borehole pipe in large S-shaped in identical heating process, there is a difference in the degree of obliquity increase, the latter is more serious. Therefore, it can be predicted that the flow resistance caused by obliquity change in the latter case could be greater.

\section{CONCLUSIONS}

The heat exchange pipes buried in backfill can generate thermal deformation under temperature difference. This could be the important factors for the performance degradation and reliability reduction of heat exchange system.

(1) Heat exchange pipes are mainly made from high density polyethylene, because of the high coefficient of thermal expansion and sensitive thermal deformation characteristics, their thermal stability will be paid more attention with the development of technologies of ground energy usage.

(2) The initial shapes of borehole pipes are the important initial condition to their thermal deformation behavior during heating process. Moreover, the initial bending of borehole pipes are objective and necessary, which will help to avoid the failing of pipe joint from contraction.

(3) Reasonable technologies of backfill and borehole pipe installation, as the guarantee for avoiding the performance degradation or failure of heat exchange system, are especially important.

\section{$\mathrm{V}$ ACKNOWLEDGEMENT}

The authors gratefully acknowledge the financial support from the NSFC (National Natural Science Foundation of China) under the grant No. 41072198.

\section{REFERENCES}

[1] Gao, Q., Li, M., Yu, M., Spitler, J.D., Yan, Y.Y.. Review of development from GSHP to UTES in China and other countries. Renewable and Sustainable Energy Reviews, 13(6-7), pp.1383-1394, 2009.

[2] Libel, V., Reuss, M.. Pe-x borehole heat exchangers for high temperature UTES applications. Proceedings of the 10th international conference on thermal energy storage-ecostock, Pomona, New Jersey, USA, 2006.

[3] F.Ochs, W.Heidemann, H.Müller-Steinhagen. Effective thermal conductivity of moistened insulation materials as a function of temperature. International Journal of Heat and Mass Transfer, 51(3-4), pp.539-552, 2008

[4] Yang, D.Y., Wu, J.Q., Qian, J.W.. A research on the 3D reconstruction of the shape of the endoscope. Chinese Journal of Applied Sciences, 21(4), pp.406-410, 2003.

[5] Tan, M.L., Wang, X.W.. A set of efficient displacement functions for arbtrarily spatial curved rod elements. Chinese Journal of Engineering Mechanics 21(3), pp.134-137, 2004.

[6] Wang Youtang, Gao Qing, Zhu Xiaolin, Yu, Ming. The study on measuring method of heat exchange pipe deformation and displacement based on thermal strain. Proceedings of the 2nd International Conference on Electronic and Mechanical Engineering and Information Technology, EMEIT, pp.1794-1798, 2012.

[7] Lenarduzzi, F.J., Cragg, C.B., Radhakrishna, H.S.. Importance of grouting to enhance the performance of earth energy systems. ASHRAE Transactions 106, pp.424-434, 2000. 